OCCUPATIONAL LUNG DISEASE

\title{
Lack of association between antioxidant gene polymorphisms and progressive massive fibrosis in coal miners
}

\author{
B Yucesoy, V J Johnson, M L Kashon, K Fluharty, V Vallyathan, M I Luster
}

See end of article for

authors' affiliations

Correspondence to:

B Yucesoy, PhD, Toxicology

and Molecular Biology

Branch, Health Effects

Laboratory Division,

National Institute for

Occupational Safety and

Health, 1095 Willowdale

Road, West Virginia

26505-2888 USA;

yab7@cdc.gov

Received 24 May 2004

Accepted 8 February 2005
Thorax 2005;60:492-495. doi: 10.1136/thx.2004.029090

Background: Oxidative stress plays a major role in the pathogenesis of interstitial lung diseases. The antioxidant enzymes glutathione S-transferases (GST) and manganese superoxide dismutase (MnSOD) are important components of lung defence against oxidative stress, and polymorphisms in the genes which regulate their expression may represent important disease modifiers.

Methods: A matched case-control study was conducted to determine the influence of the GSTPI, GSTT1 and MnSOD polymorphisms on susceptibility to progressive massive fibrosis (PMF). Seven hundred excoal miners were included in the study; 350 were classified as PMF cases while 350 with a similar underground mining tenure but no clinical or histological evidence of lung disease served as controls. Genotype analysis was performed on genomic DNA, using a $5^{\prime}$ nuclease PCR assay.

Results: None of the individual investigated polymorphisms and two-way gene-gene interactions had a statistically significant association with PMF.

Conclusion: The results of this study suggest that polymorphic genotypes within the GST gene cluster and MnSOD do not affect individual susceptibility to PMF.
$\mathrm{P}$ rogressive massive fibrosis (PMF), also referred to as complicated pneumoconiosis, is a severe form of coal workers' pneumoconiosis (CWP) characterised by severe scarring leading to obliteration of normal lung structures. Although several factors have been implicated, cumulative dust exposure is the most important factor in the pathogenesis of PMF. ${ }^{1}$ Recent studies suggest that oxidative stress plays an important role in the pathogenesis of pulmonary fibrosis, affecting fibroblast proliferation, apoptosis, and the cytokine microenvironment. ${ }^{23}$ This is especially relevant for the lung which is exposed to oxygen, oxidant pollutants, and endogenous oxidants produced by inflammatory cells. ${ }^{4}$ Many chemical and physical agents in the environment including mineral dusts are potent generators of reactive oxygen species (ROS). In response to these agents, various enzymatic and non-enzymatic defence systems help to protect cells and tissues from oxidative damage, and it is possible that genetically acquired variations in these systems account for inter-individual variation in the response to oxidative stress. In this respect, there is substantial evidence that antioxidant genes such as glutathione S-transferases (GST) and manganese superoxide dismutase (MnSOD), which are important components of lung defence in response to oxidative stress, are highly polymorphic. ${ }^{5} 6$

The GSTs, a super family of enzymes consisting of alpha, $\mathrm{mu}$, pi, theta, kappa, zeta, sigma, omega and delta families, are critical in the conversion of many reactive electrophilic compounds to less reactive metabolites which are excreted as glutathione conjugates. Several common variants of GSTs have been well characterised and are associated with certain diseases. ${ }^{6}$ The homozygous null GSTT1 genotype has been associated with asthma and cancer. ${ }^{7-9}$ A single nucleotide polymorphism in the GSTPI, resulting in amino acid substitution at codon 105 ( Ile $\rightarrow$ Val), results in altered catalytic activity ${ }^{10}$ and has been associated with lung, bladder, and oesophageal cancers, as well as chronic obstructive pulmonary disease (COPD). ${ }^{11-14}$ The superoxide dismutase family including MnSOD, copper zinc SOD, and extracellular SOD are the first line antioxidant defences and provide cellular protection against damage due to reactive oxygen species, especially in the lung. ${ }^{5}$ Exposure to fibrogenic mineral dusts has been reported to cause an increase in MnSOD enzyme activity. ${ }^{15}$ A substitution (Val $\rightarrow$ Ala) at the -9 position of the human $M n S O D$ gene may cause decreased mitochondrial transport of the molecule. ${ }^{16}$ Recent studies suggested that individuals with the Val allele containing genotypes are at a higher risk for developing cardiomyopathy and lung cancer. ${ }^{17} 18$

In order to investigate whether polymorphisms of the antioxidant genes are associated with the development of PMF, functional polymorphisms for the GSTP1, GSTT1 and $M n S O D$ genes were examined in a large well defined population of ex-coal miners presenting with coal dust induced PMF.

\section{METHODS}

\section{Study population}

Associations between antioxidant gene polymorphisms and PMF were investigated in a population consisting of a subgroup of 700 ex-underground coal miners who participated in the National Coal Workers Autopsy Study (NCWAS). Necroscopic samples were collected from 6580 white male underground miners from 1972 to 1996, and 525 cases with histologically confirmed PMF were re-reviewed and graded for CWP and other disease status without any prior knowledge of exposure and demographic information according to the criteria and protocol developed by a joint committee of the College of American Pathologists and the National Institute for Occupational Safety and Health. ${ }^{19}$ A total of 175 cases were excluded on the basis having conglomerate silicosis. This left 350 cases with highly coal dust pigmented fibrotic lesions with irregular deposition of collagen that

Abbreviations: CWP, coal workers' pneumoconiosis; PMF, progressive massive fibrosis; ROS, reactive oxygen species; SOD, superoxide dismutase 


\begin{tabular}{|c|c|c|c|}
\hline Gene & Mutation & & Probe and primer sequence \\
\hline \multirow[t]{2}{*}{ GAPDH } & Housekeeping gene & $\begin{array}{l}\text { Probe } \\
\text { Primer-F }\end{array}$ & $\begin{array}{l}\text { VIC-CCCCTGGCCAAGGT-MGB } \\
\text { TGCACCACCAACTGCTIAGC }\end{array}$ \\
\hline & & Primer-R & CACGATACCAAAGTTGTCATGGA \\
\hline \multirow[t]{2}{*}{ GSTTI } & Deletion & $\begin{array}{l}\text { Probe } \\
\text { Primer-F }\end{array}$ & $\begin{array}{l}\text { FAM-TAGCCAGGGCCCC-MGB } \\
\text { GTGCTGTGGGCAGGTGAAC }\end{array}$ \\
\hline & & Primer-R & GGCAGCATAAGCAGGACTTCAG \\
\hline \multirow[t]{4}{*}{ GSTP1 } & $\mathrm{Ile} \rightarrow \mathrm{Val}$ & Probe-lle & VIC-TGCAAATACATCTCC-MGB \\
\hline & & Probe-Val & FAM-CTGCAAATACGTCTCC-MGB \\
\hline & & Primer-F & CCTGGTGGACATGGTGAATG \\
\hline & & Primer-R & TGGTGCAGATGCTCACATAGTG \\
\hline \multirow[t]{4}{*}{$\mathrm{MnSOD}$} & $A \rightarrow V$ & Probe-V & FAM-CCAAAACCGGAGCCA-MGB \\
\hline & & Probe-A & VIC-CCCAAAGCCGGAGC-MGB \\
\hline & & Primer-F & GGCTGTGCTTTCTCGTCTTCA \\
\hline & & Primer-R & TCTGCCTGGAGCCCAGATAC \\
\hline
\end{tabular}

measured more than $1 \mathrm{~cm}$, thus meeting the criteria of classical PMF. Control miners with similar exposure histories but without apparent pulmonary disease or inflammation were matched for age and years of mining tenure.

\section{DNA preparation and genotyping}

Genomic DNA was prepared from formalin fixed, paraffin embedded lung tissue blocks following microwave deparaffinisation using a DNA isolation kit (Qiagen, Chatsworth, CA, USA), according to the manufacturer's instructions. Genotype analysis was performed on genomic DNA using a 5' nuclease PCR assay (Taqman ${ }^{\circledR}$ ). Primers and probes were designed using Assay-by-Design service (PE Applied Biosystems, Foster City, CA, USA). Table 1 shows the primer and probe sequences for each polymorphism. PCR amplification was performed in a volume of $25 \mu$ l containing $10 \mathrm{ng}$ genomic DNA, $12.5 \mu \mathrm{l} 2 \mathrm{X}$ Taqman Universal Master Mix (PE Applied Biosystems, Foster City, CA, USA), $200 \mathrm{nM}$ probe, and $900 \mathrm{nM}$ primer. Cycling conditions were $50^{\circ} \mathrm{C}$ for $2 \mathrm{~min}$, $95^{\circ} \mathrm{C}$ for $10 \mathrm{~min}$, followed by 50 cycles at $92^{\circ} \mathrm{C}$ for $30 \mathrm{~s}$ and $60^{\circ} \mathrm{C}$ for $1 \mathrm{~min}$. Amplification was performed using an iCycler IQ (Biorad Laboratories, Hercules, CA, USA) real time thermal cycler. GAPDH probe was used as internal control for the deletion polymorphism of GSTT1. Positive (DNA, freshly obtained from human blood samples) and negative controls were used within each run of PCR amplification. All samples with ambiguous results were repeated as were a random selection of $10 \%$ of all samples to ensure laboratory quality control (always $<1 \%$ ). Ten percent of the samples could not be genotyped due to poor DNA quality which is consistent with the studies sampling fixed tissues. ${ }^{20}$ Unsuccessful isolations were slightly more likely to occur in cases due to the tissue quality as a result of extensive fibrotic lesion.

\section{Statistical analysis}

Individuals from the PMF population $(\mathrm{n}=350)$ were matched with individuals free of PMF for age and years of underground mining. Matching was performed using a macro-program (Match) written in SAS (Cary, NC, USA) by Kosanke and Bergstralh and made available through the
Division of Biostatistics at the Mayo Clinic (Rochester, MN, USA).

Analyses for associations were performed using conditional logistic regression using STATA version 8.0 (Stata Corporation, College Station, TX, USA). ${ }^{21}$ This analysis uses only complete matched pairs in determining an estimate of the association. As unsuccessful genotyping of subjects did not occur in the same individuals for every gene, each analysis does not necessarily have the same sample size. However, the reported frequencies for each genotype are based on all successfully genotyped samples. The effects of smoking status and pack-years were examined to determine the influence of smoking on potential associations. However, as no substantive differences in the results occurred, unadjusted odds ratios are reported. Analyses were extended to examine all possible two-way gene-gene interactions.

\section{RESULTS}

A summary of the demographic characteristics of the study population is presented in table 2 .

The genotype frequencies for the polymorphisms are shown in table 3. No significant deviation of genotype frequencies from Hardy-Weinberg equilibrium was noted in either the control or PMF groups. The allele frequencies for GSTP1, GSTT1 and MnSOD in the control population were similar to those determined in other studies involving white populations. ${ }^{22} 23$ This study failed to find differences in the genotype frequencies or the allelic frequencies between PMF cases and controls for the GSTT1, GSTPI or MnSOD (table 3). Furthermore, no significant gene-gene interactions were detected (data not shown).

\section{DISCUSSION}

Reactive oxygen species play a central role in the pathogenesis of a variety of interstitial lung diseases. ${ }^{25}$ Both experimental and human studies have suggested that exposure to mineral dusts generate ROS which are implicated directly in the pathogenesis of CWP and PMF. ${ }^{3425}$ The ROS generating capacity of macrophages and plasma glutathione peroxidase activity of subjects exposed to coal dust also revealed a correlation with disease severity. ${ }^{24} 26$ Although several studies have supported a role for imbalances in

Table 2 Mean (SD) characteristics of the participants in the study groups

\begin{tabular}{lllll}
\hline & No of cases & Age & Years of smoking & Years of exposure \\
\hline Controls & 350 & $70.0(8.8)$ & $16.6(18.1)$ & $33.1(11.6)$ \\
PMF & 350 & $70.1(8.9)$ & $16.0(18.8)$ & $33.1(11.7)$ \\
\hline
\end{tabular}


Table 3 Distribution of GSTT1, GSTP1 and MnSOD genotypes in the study groups*

\begin{tabular}{|c|c|c|c|}
\hline Genotype & $\begin{array}{l}\text { PMF } \\
\text { n (\%) }\end{array}$ & $\begin{array}{l}\text { Controls } \\
\text { n (\%) }\end{array}$ & OR $(95 \% \mathrm{Cl})$ \\
\hline \multicolumn{4}{|l|}{ GSTII } \\
\hline Positive & $244(80.3)$ & $255(77.3)$ & 1.0 (ref) \\
\hline Null & $60(19.7)$ & $75(22.7)$ & $0.84(0.54$ to 1.30$)$ \\
\hline \multicolumn{4}{|l|}{ GSTP1 } \\
\hline $\mathrm{lle} / \mathrm{lle}$ & $129(44.2)$ & $142(44.1)$ & 1.0 (ref) \\
\hline $\mathrm{lle} / \mathrm{Val}$ & $118(40.4)$ & $134(41.6)$ & 0.93 (0.64 to 1.32 ) \\
\hline $\mathrm{Val} / \mathrm{Val}$ & $45(15.4)$ & 46 (14.3) & 0.99 (0.60 to 1.62$)$ \\
\hline \multicolumn{4}{|l|}{ MnSOD } \\
\hline AA & $69(23.2)$ & $72(21.9)$ & 1.0 (ref) \\
\hline AV & $138(46.5)$ & $168(51.2)$ & 0.85 (0.55 to 1.29$)$ \\
\hline W & $90(30.3)$ & $88(26.8)$ & $0.94(0.59$ to 1.51$)$ \\
\hline
\end{tabular}

antioxidant/oxidant systems in the incidence, prevalence, and severity of respiratory diseases, ${ }^{27}$ only limited studies have evaluated the association between antioxidant gene polymorphisms and pulmonary fibrosis ${ }^{23} 28$ and, to our knowledge, this is the first case-control study to investigate possible associations between PMF and antioxidant gene polymorphisms.

None of the investigated polymorphisms had a statistically significant effect on PMF when studied individually or in two-gene combinations. This result supports and extends findings from a study in which no associations were found in the genotype frequency of MnSOD or GSTTI between Chinese miners with CWP and miners without CWP. ${ }^{28}$ In a multifactorial disease such as PMF, it is likely that genetic susceptibility is dependent on the effect of multiple gene polymorphisms acting in combination with exposure. Previous reports have shown that combinations of GST polymorphisms-rather than individual genotypes-have associations with lung cancer and a rapid decline in lung function. ${ }^{29}{ }^{30}$ To test this in our population, gene-gene interactions were analysed but no significant association with disease was found.

A crucial problem in case-control studies has been small sample size resulting in insufficient statistical power to determine whether an association between a variant and a disease exists. The present matched case-control study had sufficient power to detect an OR of 1.8 if it existed. Based on this, the present study is able to report no association between GST and MnSOD genotypes and PMF with sufficient statistical power. Although our study design is not appropriate for such evaluation due to presence of only severe cases, inter-individual differences in antioxidant production may influence disease progression by acting as disease modifiers. Increased risk could depend also on genetic variants involved in the modulation of extracellular matrix or fibrogenesis which are not necessarily affected by a GST expression such as platelet derived growth factor, matrix metalloproteinases, fibronectin, and transforming growth factor- $\beta$.

In conclusion, none of the individual GST or MnSOD genotypes or two-way gene-gene interactions had a statistically significant association with PMF. Although we failed to show an association, our findings do not exclude the possibility that, together with other genetic and environmental impairments, antioxidant genes may play a significant role in the severity of inflammatory or fibrotic lung diseases.

\section{ACKNOWLEDGEMENTS}

The authors thank Patsy A Willard for excellent technical assistance in the preparation of tissues and Drs Michael Andrew and Omur C Elci for their excellent review of the manuscript during preparation.

\section{Authors' affiliations}

B Yucesoy, V J Johnson, K Fluharty, M I Luster, Toxicology and Molecular Biology Branch, Health Effects Laboratory Division, National Institute for Occupational Safety and Health, Morgantown, West Virginia, USA

M L Kashon, Biostatistics Branch, Health Effects Laboratory Division, National Institute for Occupational Safety and Health, Morgantown, West Virginia, USA

V Vallyathan, Pathology and Physiology Research Branch, Health Effects Laboratory Division, National Institute for Occupational Safety and Health, Morgantown, West Virginia, USA

\section{REFERENCES}

1 Green FHY, Vallyathan V. Coal worker's pneumoconiosis due to other carbonaceous dusts. In: Churg A, Green FHY, eds. Pathology of occupational lung disease. Baltimore: Williams \& Wilkins, 1998:158-70.

2 Mastruzzo C, Crimi N, Vancheri C. Role of oxidative stress in pulmonary fibrosis. Monaldi Arch Chest Dis 2002;57:173-6.

3 Schins RP, Borm PJ. Mechanisms and mediators in coal dust induced toxicity: a review. Ann Occup Hyg 1999;43:7-33.

4 Nemery B, Bast A, Behr J, et al. Interstitial lung disease induced by exogenous agents: factors governing susceptibility. Eur Respir J 2001;18:30-42.

5 Kinnula VL, Crapo JD. Superoxide dismutases in the lung and human lung diseases. Am J Respir Crit Care Med 2003;167:1600-19.

6 Hayes JD, Strange RC. Glutathione S-transferase polymorphisms and their biological consequences. Pharmacology 2000;61:154-66.

7 Tamer L, Calikoglu M, Ates NA, et al. Glutathione-S-transferase gene polymorphisms (GSTT1, GSTM1, GSTP1) as increased risk factors for asthma. Respirology 2004:9:493-8.

8 Pemble S, Schroeder KR, Spencer SR, et al. Human glutathione S-transferase theta (GSTT1): cDNA cloning and the characterization of a genetic polymorphism. Biochem J 1994;300:271-6.

9 Sweeney C, Farrow DC, Schwartz SM, et al. Glutathione S-transferase M1, $\mathrm{Tl}$, and $\mathrm{Pl}$ polymorphisms as risk factors for renal cell carcinoma: a casecontrol study. Cancer Epidemiol Biomarkers Prev 2000;9:449-54.

10 Ali-Osman F, Akande O, Antoun G, et al. Molecular cloning, characterization, and expression in Escherichia coli of full-length cDNAs of three human glutathione S-transferase Pi gene variants. Evidence for differential catalytic activity of the encoded proteins. J Biol Chem 1997;272:10004-12.

11 Harries LW, Stubbins MJ, Forman D, et al. Identification of genetic polymorphisms at the glutathione $\mathrm{S}$-transferase $\mathrm{Pi}$ locus and association with susceptibility to bladder, testicular and prostate cancer. Carcinogenesis 1997; 18:641-4.

12 Seidegard J, Pero RW, Miller DG, et al. A glutathione transferase in human leukocytes as a marker for the susceptibility to lung cancer. Carcinogenesis 1986;7:751-3.

13 van Lieshout EM, Roelofs HM, Dekker S, et al. Polymorphic expression of the glutathione S-transferase P1 gene and its susceptibility to Barrett's esophagus and esophageal carcinoma. Cancer Res 1999;59:586-9.

14 Ishii T, Matsuse T, Teramoto S, et al. Glutathione S-transferase P1 (GSTP1) polymorphism in patients with chronic obstructive pulmonary disease. Thorax 1999;54:693-6.

15 Janssen YM, Marsh JP, Driscoll KE, et al. Increased expression of manganesecontaining superoxide dismutase in rat lungs after inhalation of inflammatory and fibrogenic minerals. Free Radic Biol Med 1994;16:315-22.

16 Shimoda-Matsubayashi S, Matsumine H, Kobayashi T, et al. Structural dimorphism in the mitochondrial targeting sequence in the human manganese superoxide dismutase gene. A predictive evidence for conformational change to influence mitochondrial transport and a study of allelic association in Parkinson's disease. Biochem Biophys Res Commun 1996;226:561-5. 
17 Hiroi $\mathrm{S}$, Harada $\mathrm{H}$, Nishi $\mathrm{H}$, et al. Polymorphisms in the SOD2 and HLA-DRB genes are associated with nonfamilial idiopathic dilated cardiomyopathy in Japanese. Biochem Biophys Res Commun 1999;261:332-9.

18 Wang LI, Miller DP, Sai Y, et al. Manganese superoxide dismutase alanine-tovaline polymorphism at codon 16 and lung cancer risk. J Natl Cancer Inst 2001:93:1818-21.

19 Kleinerman J, Green F, Laqueur W. Pathology standards for coal workers' pneumoconiosis. Pathol Lab Med 1979;103:375-431.

20 Gioia L, Vogt $\sqcup$, Freeman WM, et al. PCR-based apolipoprotein E genotype analysis from archival fixed brain. J Neurosci Meth 1998:80:209-14.

21 Hosmer DW, Lemeshow S. Applied logistic regression. 2nd ed. New York: John Wiley \& Sons Inc, 2000.

22 Garte S, Gaspari L, Alexandrie AK, et al. Metabolic gene polymorphism frequencies in control populations. Cancer Epidemiol Biomarkers Prev 2001;10:1239-48.

23 Hirvonen A, Tuimala J, Ollikainen T, et al. Manganese superoxide dismutase genotypes and asbestos-associated pulmonary disorders. Cancer Lett 2002; 178:71-4.

24 Wallaert B, Lassalle $\mathrm{P}$, Fortin F, et al. Superoxide anion generation by alveolar inflammatory cells in simple pneumoconiosis and in progressive massive fibrosis of nonsmoking coal workers. Am Rev Respir Dis 1990;141:129-33.

25 Vallyathan V, Goins M, Lapp LN, et al. Changes in bronchoalveolar lavage indices associated with radiographic classification in coal miners. Am J Respir Crit Care Med 2000;162:958-65.

26 Nadif $R$, Bourgkard E, Dusch $M$, et al. Relations between occupational exposure to coal mine dusts, erythrocyte catalase and $\mathrm{Cu}^{++} / \mathrm{Zn}^{++}$superoxide dismutase activities, and the severity of coal workers' pneumoconiosis. Occup Environ Med 1998;55:533-40.

27 MacNee W. Oxidative stress and lung inflammation in airways disease. Eur J Pharmacol 2001;429:195-207.

28 Zhai R, Liu G, Ge X, et al. Genetic polymorphisms of MnSOD, GSTMI, GSTT1, and OGG1 in coal workers' pneumoconiosis. J Occup Environ Med 2002;44:372-7.

$29 \mathrm{He} \mathrm{JQ}$, Ruan J, Connett JE, et al. Antioxidant gene polymorphisms and susceptibility to a rapid decline in lung function in smokers. Am J Respir Crit Care Med 2002; 166:323-8.

30 Saarikoski ST, Voho A, Reinikainen M, et al. Combined effect of polymorphic GST genes on individual susceptibility to lung cancer. Int J Cancer 1998;77:516-21.

\section{LUNG ALERT}

A new class of antimycobacterial drugs: the diarylquinolines

$\Delta$ Andries K, Verhasselt P, Guillemont J, et al. A diarylquinoline drug active on the ATP synthase of Mycobacterium tuberculosis. Science 2005;307:223-7

O

ver three million people die from tuberculosis (TB) every year, and drug resistance is

an increasing problem. This paper reports the development of a promising new anti-

TB agent, R207910, a diarylquinoline. It acts as an inhibitor of mycobacterial ATP synthase, a different mechanism of action from any other anti-TB drug. This minimises the potential for cross-resistance and suggests that R207910 may prove effective in the treatment of MDR-TB, as demonstrated by the authors in vitro. It is specific in activity to mycobacteria, including the opportunistic species MAC and $M$ kansasii, with in vivo bactericidal activity against $M$ tuberculosis in a murine model.

Animal and human pharmacokinetic and pharmacodynamic studies show that R207910 has a long plasma half life, good tissue penetration, and potential for a dose regimen of less than five doses per week, making it ideal for DOT. Human studies have so far shown good tolerability to a treatment dose with no major adverse events.

The authors have shown that R207910 is an effective antimycobacterial agent with pharmacokinetic properties favouring good treatment adherence. It remains to be seen if these results are confirmed in clinical trials. 